\title{
Benjamin Franklin e a formação de temporais com raios e trovões: tradução comentada de uma carta a John Mitchel $^{+*}$
}

\author{
Breno Arsioli Moura ${ }^{l}$ \\ Centro de Ciências Naturais e Humanas - CCNH \\ Universidade Federal do ABC - UFABC \\ Thátyusce Bonfim ${ }^{2}$ \\ Universidade Federal do ABC - UFABC \\ Santo André - SP
}

\section{Resumo}

Neste artigo, apresentamos uma tradução integral e comentada da carta escrita por Benjamin Franklin (1706-1790) e endereçada a John Mitchel (1711-1768), contendo sua explicação para a formação de temporais com raios e trovões. Trata-se da primeira vez que este texto é traduzido para o português brasileiro. Na carta, redigida no auge dos estudos de Franklin em eletricidade, o norte-americano utilizou um estilo característico de muitos escritos do século XVIII, partindo de evidências experimentais e seguindo um passo-a-passo indutivo. Para corroborar suas proposições, ele valeu-se extensivamente de sua teoria de um único fluido elétrico, então recém-elaborada.

Palavras-chave: Franklin; Eletricidade; Temporais; Raios; Trovões.

\begin{abstract}
In this paper, we present a complete and commented translation to Portuguese of Benjamin Franklin's letter to John Mitchel, in which he discussed his explanation for the formation of thunder-gusts and
\end{abstract}

\footnotetext{
+ Benjamin Franklin and the thunder-gusts formation: a commented translation of Benjamin Franklin's letter to John Mitchel

* Recebido: novembro de 2016.

Aceito: junho de 2017.

1 E-mail: breno.moura@ufabc.edu.br

2 E-mail: thaty.bonfim@gmail.com
} 
lightning. This is the first time this letter is translated to Brazilian Portuguese. In the letter, written during the most productive period of Franklin's studies on electricity, the American natural philosopher used a common style of writing of the 18th century, based on experimental evidences and following inductive steps. In order to support his propositions, he made extensive use of his recent theory of one electrical fluid.

Keywords: Franklin; Electricity; Thunder-gusts; Lightning; Thunder.

\section{Introdução}

Na História da Ciência, Benjamin Franklin (1706-1790) é comumente associado ao desenvolvimento de conceitos da eletricidade e à invenção do para-raios, esta última concebida a partir de suas investigações sobre as tempestades. Entretanto, no contexto escolar, suas realizações são geralmente relatadas por meio de anedotas descontextualizadas e anacrônicas, como os experimentos com pipas (SILVA; PIMENTEL, 2008a). Creditamos essas abordagens, dentre outras causas, ao desconhecimento a respeito dos trabalhos de Franklin. No contexto brasileiro, em especial, o pouco contato com os escritos de Franklin é prejudicado pelo fato de nenhuma de suas obras científicas ter sido traduzida do inglês. No caso das fontes secundárias, o cenário não é menos preocupante, uma vez que poucos trabalhos foram feitos sobre esse autor por pesquisadores brasileiros (SILVA; PIMENTEL, 2008a; 2008b; PYENSON, 1998).

O propósito deste artigo é facilitar o acesso direto a uma fonte primária de Franklin, apresentando um aspecto de seu trabalho, a partir da tradução integral e comentada de uma de suas dezenas de cartas escritas no século XVIII a correspondentes da Europa e dos Estados Unidos $^{3}$. A carta em questão é datada de 29 de abril de 1749 e foi endereçada a John Mitchel (1711-1768) ${ }^{4}$. Nela, Franklin versou sobre a formação de temporais com raios e trovões, oferecendo suas primeiras ideias acerca da natureza elétrica dos raios.

A tradução comentada da carta de Franklin busca trazer subsídios para uma discussão mais aprofundada de suas realizações e, de maneira geral, da história da ciência e da eletricidade no século XVIII. Atualmente, é consenso que introduzir conteúdos históricos em aulas de ciências pode ampliar o leque cultural e conceitual de professores e alunos, fomentando uma visão mais adequada da natureza do conhecimento científico (ALLCHIN, 2013, p. 3-4). Dessa maneira, a tradução pode auxiliar no desenvolvimento de atividades educacionais que privilegiem

\footnotetext{
${ }^{3}$ Franklin nunca escreveu um tratado de eletricidade. Suas ideias foram divulgadas por meio de suas cartas, reunidas em 1751 e publicadas por Peter Collinson (1694-1768), sob o título Experiments and observations on eletricity, made at Philadelphia in America. Para este trabalho, foi utilizada a versão de 1769, a quarta versão inglesa e a primeira editada pelo próprio Franklin (FRANKLIN, 1769).

${ }^{4}$ Mitchel era americano e membro da Royal Society (COHEN, 1956, p. 464).
} 
uma visão plural da ciência no século XVIII, uma vez que as explicações elaboradas por Franklin estão intimamente associadas a seu pensamento sobre eletricidade, bem como às bases teóricas, experimentais e epistemológicas da filosofia natural no período.

No Brasil, a falta de fontes primárias e secundárias disponíveis em português é citada de forma recorrente por historiadores da ciência e educadores como um entrave para a introdução da história e filosofia da ciência no ensino (MARTINS, 2006, p. xxvii-xxviii; BATISTA et. al., 2015, p. 668). Por essa razão, as traduções têm se tornado uma linha de trabalho permanente, especialmente aquelas acrescidas de comentários dos tradutores, em muitos casos, historiadores da ciência. Para situações de ensino, as traduções comentadas revelam-se potencialmente úteis, uma vez que não apenas apresentam o texto final traduzido, como também incluem percepções e interpretações dos historiadores que as traduziram. Por essa razão, o educador dispõe de um conjunto de informações que não necessariamente estão evidentes no texto.

As traduções implicam um trabalho de "intepretação e avaliação" (KRAGH, 2001, p. 148). Isso significa que nenhuma tradução é um trabalho imparcial, destituído das posições científicas e epistemológicas de seu tradutor. Pelo contrário, uma boa tradução é fruto de um profundo mergulho nas problemáticas do texto, de seu autor e do período em questão, em que o tradutor se propõe a analisar diacronicamente os termos e ideias, buscando entendê-los à luz do momento em que foram propostos. Nesse sentido, as traduções apresentam não apenas material em outra língua, mas um estudo historiográfico sobre os assuntos nele contidos.

Considerando os argumentos anteriores, a tradução comentada da carta de Franklin foi fundamentada em um detalhado estudo da ciência e da eletricidade no século XVIII. Foram analisados outros textos do autor e fontes secundárias de referência sobre o período (COHEN, 1956; 1996; HEILBRON, 1979; WHITTAKER, 1951). O resultado apresentado nesse artigo é apenas parte de um projeto mais amplo, que busca traduzir outras cartas de Franklin e contribuir para um entendimento mais adequado da filosofia natural no século XVIII 5 . A tradução comentada é precedida de um preâmbulo sobre o contexto de publicação da carta, bem como sobre o próprio Franklin, a fim de introduzir o leitor aos assuntos abordados no texto.

\section{A carta a John Mitchel: explicando a formação de temporais com raios e trovões}

Franklin nasceu em Boston e era o mais novo de 9 irmãos. Devido ao seu gosto pela leitura, foi treinado para trabalhar no ramo da tipografia, profissão que exerceu até seus 41 anos de idade. No auge de sua carreira e já com a sua própria loja de tipografia, Franklin fazia a publicação do jornal Pennsylvania Gazette e nele divulgava o almanaque Poor Richard, de grande sucesso entre os leitores. Apesar de já ter sido um estudioso desde jovem, o almanaque

\footnotetext{
5 O projeto tem financiamento da Fundação de Amparo à Pesquisa do Estado de São Paulo (FAPESP). Atualmente, estamos finalizando a tradução comentada de outras duas cartas de Franklin, bem como de um documento mais extenso, em que apresentou uma teoria de eletricidade mais consolidada.

${ }^{6}$ O jornal nasceu em 1728 pelas mãos de Samuel Keimer (1689-1742) e foi comprado em 1729 por Franklin e Hugh Meredith (c. 1697-c. 1749). Sua publicação perdurou até o ano de 1800.
} 
exigia de Franklin o estudo dos mais variados temas, o que o levou a criar um grupo de estudos denominado JUNTO e, mais tarde, a primeira biblioteca por subscriçãoda América, a Library Company ${ }^{7}$. Por meio dessa biblioteca, ele pôde ter contato com os mais variados materiais sobre a filosofia natural. Paralelamente às suas investigações em eletricidade, Franklin começou sua vida política. Dentre os muitos cargos ocupados por ele, foi deputado e porta voz da Pensilvânia em Londres, chegando a ser um dos redatores da declaração da independência dos Estados Unidos e da constituição americana, tendo se tornado assim um dos mais influentes americanos da história (FRANKLIN, 2005; CHAPLIN, 2006).

A carta a Mitchel não foi a primeira incursão de Franklin nos estudos sobre eletricidade. Em meados de 1745, ele já estava envolvido na realização de experimentos na área, contando com a colaboração de colegas norte-americanos, com quem formou o grupo Philadelphians ou Philadelphia Experiments. O principal objetivo do grupo era produzir e investigar os fenômenos elétricos por meio de experimentos (COHEN, 2007, p. 846). O resultado dessas primeiras investigações foi materializado em cartas escritas a Peter Collinson (1694-1768) em 1747, um dos principais correspondentes de Franklin na Grã-Bretanha. Nesses escritos iniciais, Franklin destacou o poder dos corpos pontudos em receber e transferir eletricidade e a conservação do fogo elétrico, além de estabelecer a teoria de um único fluido elétrico e da eletrização "mais" e "menos". A argumentação da carta a Mitchel originou-se diretamente desses estudos prévios na área.

Quando Franklin começou a trabalhar com eletricidade, esse campo de pesquisa estava começando a amadurecer. Até este período, os estudos em eletricidade eram escassos. Destacam as ideias de Girolamo Cardano (1501-1576) a respeito das propriedades de atração do âmbar e suas diferenças com os efeitos dos imãs ${ }^{8}$, e as de William Gilbert (1544-1603), que denominou os efeitos do âmbar de "elétricos" ". Para ele, esses fenômenos seriam ocasionados por algo material, preso ao corpo. Segundo Whittaker (1951, p. 36), Gilbert provavelmente associou a eletricidade à concepção de humores $^{10}$, amplamente aceita na época. A eletricidade seria um

\footnotetext{
${ }^{7}$ Ainda funcionando por subscrição, hoje a biblioteca é aberta ao público. Os materiais se concentram na história da sociedade e cultura americana do século XVII ao século XIX.

${ }^{8}$ Cardano notou cinco diferenças entre os efeitos do âmbar e os dos imãs: o âmbar atraía muitos tipos de corpos, enquanto o imã apenas o ferro; a atração entre o imã e o ferro é mútua, o que não acontece com o âmbar; a magnetita atua através de objetos, o que não acontece com o âmbar; a magnetita atrai somente em direção a seus polos, o âmbar em todas as direções; a força do âmbar aumenta quando este é atritado ou aquecido, o que não acontece com os imãs (HEILBRON, 1979, p. 174).

${ }^{9}$ O termo electric foi usado pela primeira vez em 1646 por Thomas Browne (1605-1682) (WHITTAKER, 1951, p. 35, n. 4). A palavra, do grego elektron, significa "âmbar" ou "semelhante ao âmbar" (Online Etymology Dictionary, http://www.etymonline.com, acesso em maio de 2017).

10 Nesta concepção, o corpo humano seria preenchido por quatro humores: fleuma, bílis amarela, bílis negra e sangue. A saúde do corpo estaria relacionada ao equilíbrio dos humores; por sua vez, a doença, seria causada pelo excesso ou falta de um ou mais humores no corpo.
} 
tipo particular de humor, como um eflúvio emanando do corpo e atuando sobre os corpos vizinhos. A ideia de eflúvio colocada por Gilbert permaneceu ao longo do século XVII com algumas modificações. De forma geral, não havia grande interesse pelos fenômenos elétricos e poucos filósofos naturais dedicaram sua atenção a esse tema neste período. Destacam-se, contudo, os trabalhos de Otto Von Guericke (1602-1686), que apresentou sua "máquina elétrica", um tipo de gerador eletrostático constituído de uma esfera de enxofre manipulada com uma manivela. Atritada, a esfera produzia choques quando em contato com outros objetos.

A partir do século XVIII, os estudos sobre eletricidade começaram a traçar um novo rumo. Nesse período, a filosofia natural passou por importantes transformações na Europa, especialmente na Grã-Bretanha. Enquanto no período anterior, ela estava restrita aos meios acadêmicos e aos intelectuais, iniciou-se no século XVIII um processo de popularização e divulgação das realizações dos filósofos naturais. A valorização da filosofia natural como um produto cultural e suas aplicações práticas a aproximou de construtores de instrumentos, artesãos, tecelões, relojoeiros etc.; indivíduos que antes aprendiam seus ofícios como herança de família (HANS, 1998). Além disso, houve uma forte influência dos estudos e estilos de estudar o mundo natural de Isaac Newton (1642-1727) e dos vários Newtonianismos que se instalaram na Europa ao longo do século XVIII (SCHOFIELD, 1978; DOBBS e JACOB, 1995). Isso propagou, de maneira geral, a tendência em valorizar a experimentação e a indução na busca pelo conhecimento sobre o mundo natural. Ser um bom filósofo natural significava fazer amplo uso de experimentos para "provar" os conceitos expressados.

Atreladas a essas mudanças na filosofia natural e inspiradas no Newtonianismo, estavam as conferências populares. Por meio de experimentos de fácil manuseio e entendimento, os filósofos naturais exibiam e discutiam modelos explicativos para os fenômenos naturais. Os experimentos com forte apelo visual e sensorial tinham especial destaque (MOURA, 2008, p. 89). Nesse sentido, a eletricidade chamava atenção, uma vez que seus fenômenos reuniam estes dois elementos. No decorrer do século XVIII, diversos filósofos naturais trabalharam sobre os fenômenos elétricos, buscando estabelecer suas características principais e modelos explicativos para compreendê-los, dentre eles, Stephen Gray (1666-1736), Charles-François du Fay (1698-1739) e Jean-Antoine Nollet (1700-1770)11. Dessa maneira, Franklin começou a escrever sobre eletricidade em um período em que ela estava sob intenso detalhamento por parte de outros filósofos naturais, especialmente europeus. Foi nesse contexto que surgiram seus primeiros estudos, comunicados a Collinson no final da década de 1740 e, posteriormente, sua carta a Mitchel, a respeito da formação dos temporais com raios e trovões, objeto deste artigo.

Para formular a sua teoria de como as nuvens são eletrizadas e como as tempestades são formadas, Franklin explorou como se dava a interação entre o fogo elétrico e a água. Em

\footnotetext{
11 É possível encontrar alguns estudos historiográficos brasileiros sobre esses autores, tais como Boss e colaboradores (2012), Boss e Caluzi (2007) e Silva (2011).
} 
sua concepção, o fogo elétrico ${ }^{12}$ seria um tipo particular de matéria, presente em todos os corpos, e possuía propriedades, tais como a sutileza, elasticidade, e não poder ser criado nem destruído; já a matéria comum ou "ponderável” seria aquela que comporia os corpos naturais, como a água (COHEN, 1956, p. 306; SCHOFIELD, 1970, p. 169). Ambas se atraíam mutuamente. Ele discutiu casos que ilustravam as consequências da presença dos fogos elétrico e comum na água, e como isso resultava em temporais com raios e trovões e, consequentemente, na formação de rios e lagos. A explicação foi baseada em quatro argumentos cruciais e, resumidamente, foi a seguinte: 1) fogo elétrico e água se atraem mutuamente, e partículas de água se atraem mutuamente 2) os oceanos são formados, basicamente, por água - um "não-elétrico" - e por sal, um material "elétrico" "13 ; a interação entre esses dois materiais captura o fogo elétrico ao redor, o que deixa a água dos oceanos eletrizada e, consequentemente, seus vapores; 3) o vapor d'água do mar está eletrizado e, ao subir e formar nuvens, estas também estarão; ao entrarem em contato com outras nuvens menos eletrizadas ou montanhas, o fogo elétrico é transmitido na forma de raios; com o fogo elétrico transmitido, as partículas de água dos vapores, agora condensados e se atraindo mutuamente, caem na forma de chuva, por sua atração mútua; 4) por consequência, os raios são simplesmente a manifestação da transmissão do fogo elétrico, sendo da mesma natureza das faíscas observadas em experimentos com garrafas de Leyden ${ }^{14}$.

A descrição de Franklin é detalhada, complexa e possivelmente muito inspirada no viés newtoniano de estudar o mundo natural vigente à época ${ }^{15}$. Franklin começou em um plano microscópico, explicando as pequenas atrações e repulsões que acontecem entre as partículas

\footnotetext{
12 Em alguns textos historiográficos e até mesmo nos próprios escritos de Franklin, o leitor pode encontrar os termos "fluido elétrico" ou "matéria elétrica" ao invés de "fogo elétrico" (COHEN, 1956, p. 460, n. †). Neste artigo, mantivemos o termo utilizado por Franklin na carta a Mitchel.
}

13 No século XVIII, muitos termos utilizados na eletricidade possuíam significados diferentes dos atuais. Este é o caso dos materiais "não-elétricos" e dos "elétricos". Essa distinção, com o uso dessas palavras, foi feita pela primeira vez por John Theophilus Desaguliers (1683-1744), nas primeiras décadas desse século (WHITTAKER, 1951, p. 42). Em suma, os "não-elétricos" eram aqueles que não retinham a eletricidade por um longo período, tais como os metais. Já os "elétricos" eram aqueles que poderiam ser eletrizados e retinham a eletricidade, tais como o vidro.

14 Embora Franklin seja associado a essa constatação, outros filósofos naturais já apontavam as semelhanças entre os efeitos dos raios e das faíscas elétricas comuns. Por exemplo, no ano anterior à carta, em 1748, o filósofo natural francês Jean-Antoine Nollet já havia discutido algumas semelhanças entre as descargas elétricas e os raios em tempestades apontadas por Franklin, tais como sua capacidade para incendiar ou danificar objetos (HEILBRON, 1979, p. 340). Ademais, é importante ressaltar que Franklin ainda desenvolveria muito mais suas ideias a respeito da natureza elétrica dos raios nos escritos seguintes, sendo as apresentadas na carta a Mitchel reflexões iniciais sobre o tema.

15 A influência de Newton sobre Franklin foi descrita com minúcia por Cohen (1956). Segundo o autor, o contato de Franklin com as doutrinas newtonianas deu-se com a leitura do livro Opticks, publicado originalmente em 1704, feita entre os anos de 1746 e 1747. Como seguidor do método indutivo newtoniano, ele buscava visualizar em seus experimentos uma forma de elaborar uma hipótese que fosse capaz de descrever o fenômeno da eletricidade e, além disso, ser capaz de produzir previsões do mesmo. Essa postura fez com que ele produzisse muitos experimentos e os descrevesse em suas cartas, muitos deles sem um propósito anteriormente definido (a isso é atribuído o seu amadorismo) (COHEN, 1956, p. 206). 
de água e entre as partículas de ambos os fogos (elétrico e comum) e depois seguiu para um plano macroscópico, exemplificando os grandes efeitos causados por essas pequenas interações. A fim de justificar os argumentos que utilizou ao longo da carta, ele propôs alguns experimentos para demonstrar como ocorreriam essas interações. Ao final da carta, Franklin deu recomendações de como se proteger durante um temporal de raios e sugeriu uma explicação para a formação da aurora boreal por meio dos fenômenos elétricos.

Os resultados apresentados na carta a Mitchel compõem sua curiosa explicação para a formação dos temporais com raios e trovões, cuja tradução integral é apresentada na seção seguinte. As notas de rodapé indicadas por letras são observações feitas pelo próprio Franklin e as páginas indicadas em colchetes remetem àquelas do documento original. Termos entre colchetes foram adicionados pelos tradutores a fim de facilitar a compreensão dos argumentos ali colocados.

\section{Tradução comentada da carta de Franklin a Mitchel, a respeito da formação de tem- porais com raios e trovões}

$$
\text { [p. 39] CARTA V16 }
$$

Contendo

OBSERVAÇÕES $e$ SUPOSIÇÕES, para a formação de uma nova HIPÓTESE para explicar os diversos fenômenos dos TEMPORAIS COM RAIOS E TROVÕESa17.

\footnotetext{
16 A carta no idioma original pode ser conferida em Franklin (1769, p. 39-52).

a Temporais com trovões são chuvas repentinas com raios e trovões, que frequentemente são de curta duração, mas [que] algumas vezes produzem efeitos perniciosos.

$17 \mathrm{O}$ termo original utilizado por Franklin foi thunder-gusts, que não possui uma tradução exata para o português. Segundo dicionário Merriam-Webster, o termo significa thunderstorm with wind, o que seria, em português, o equivalente a temporal com raios, trovões e vento (http://www.merriam-webster.com/dictionary/thunder-gust, acesso em Maio de 2017). Contudo, pela descrição apresentada pelo próprio Franklin na nota de rodapé "a", ele não parece ter incluído o vento como uma propriedade relevante para o tipo de temporal que buscou descrever. Pela natureza diversificada das traduções dos termos em inglês para tempestades e temporais, e seguindo a definição do próprio Franklin, especialmente em relação à duração do fenômeno, preferimos utilizar como tradução a thunder-gusts o termo "temporal com raios e trovões".
} 


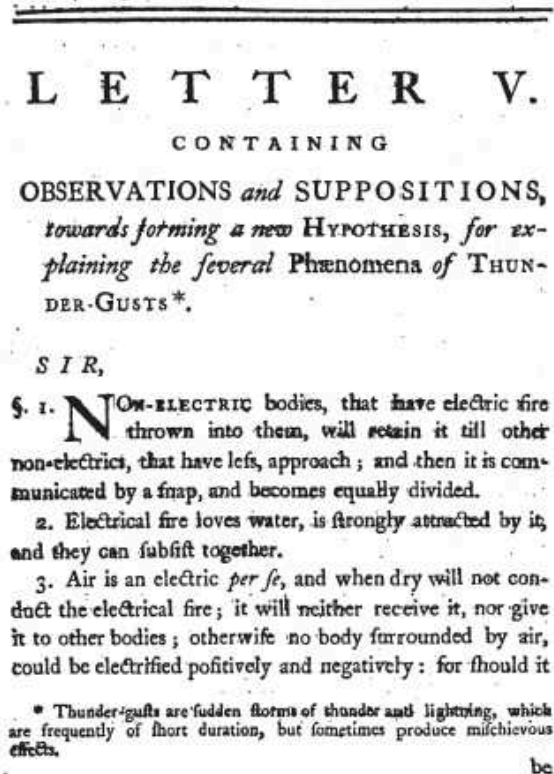

Fig. 1 - Início da quinta carta enviada por Franklin a Mitchel.

Senhor,

1. Corpos não-elétricos, que tiveram fogo elétrico lançado neles, vão retê-lo até outros corpos não-elétricos, que possuem menos [fogo elétrico], se aproximarem. E então, ele [o fogo elétrico] é transmitido por um estalo, e se torna igualmente dividido.

2. O fogo elétrico ama a água, é fortemente atraído por ela e eles podem subsistir juntos ${ }^{18}$.

3. O ar é elétrico per se, e quando seco não conduz o fogo elétrico. Ele não vai nem recebê-lo e nem doá-lo para outros corpos. Do contrário, nenhum corpo cercado por ar poderia ser eletrificado positivamente ou negativamente: pois se fosse [p. 40] tentado [eletrizar um corpo] positivamente, o ar imediatamente tomaria o [fogo elétrico] excedente; ou negativamente, o ar supriria o [fogo elétrico] deficiente ${ }^{19}$.

4. A água sendo eletrificada, os vapores que saem dela estarão igualmente eletrificados. E flutuando pelo ar na forma de nuvens, ou de outra maneira, reterão essa quantidade de fogo elétrico até que eles se encontrem com outras nuvens ou corpos não tão eletrificados, e assim transmitirão [o fogo elétrico] como acima mencionado [no item 1].

5. Cada partícula ${ }^{20}$ de matéria eletrificada é repelida por qualquer outra partícula igualmente

\footnotetext{
18 Esse é o primeiro argumento crucial de Franklin e será a base para a argumentação posterior.

19 Ou seja, se o ar fosse um condutor de eletricidade (não elétrico), ele não permitiria a eletrização de nenhum corpo que o rodeasse, uma vez que tomaria toda a eletricidade para si ou a forneceria para outro corpo facilmente. Por isso, a água atrelada ao ar é tão importante para a condução da eletricidade.

${ }^{20}$ No século XVIII, foram desenvolvidas diversas concepções sobre matéria. Assim como muitos outros filósofos naturais da época, Franklin modificou em vários momentos as suas. De maneira geral, segundo Schofield (1970,
} 
eletrificada. Desse modo, a corrente de uma nascente, naturalmente densa e contínua, quando eletrificada, vai separar e espalhar na forma de um borrão, cada gota se esforçando para se afastar de cada outra gota. Mas, retirando-se o fogo elétrico, elas irão se aproximar novamente. 6. A água sendo fortemente eletrificada (assim como quando aquecida pelo fogo comum) sobe em vapor mais copiosamente. A atração de coesão entre suas partículas sendo muito enfraquecida pelo poder oposto de repulsão introduzido com o fogo elétrico. E quando qualquer partícula [de água] é por qualquer motivo desprendida, ela é imediatamente repelida, e assim voa para o ar.

7. Partículas [de água] que estão situadas como $A$ e $B$, (Fig VI ${ }^{21}$ [Fig. 2] representando o perfil de um recipiente de água) são mais facilmente desprendidas que $C$ e $D$, pois cada uma é mantida pelo contato com somente três [partículas], enquanto $C$ e $D$ estão em contato com nove, cada ${ }^{22}$. Quando a superfície da água tem o menor movimento, partículas [p. 41] são continuamente empurradas para a situação representada por $A$ e $B$.

8. A fricção entre um [corpo] não-elétrico e um elétrico per se vai produzir fogo elétrico. Não por criá-lo, mas por coletá-lo ${ }^{23}$ : pois ele está igualmente difundido nas nossas paredes, chão, terra, e todo o conjunto de matéria comum. Assim, o giro do globo de vidro, durante a sua fricção contra o estofado, extrai o fogo [elétrico] do estofado, o estofado é abastecido a partir da armação da máquina, e aquela pelo chão onde ela está. Corte a comunicação com um vidro grosso ou cera, colocados embaixo do estofado, e nenhum fogo pode ser produzido, porque ele não pode ser coletado.

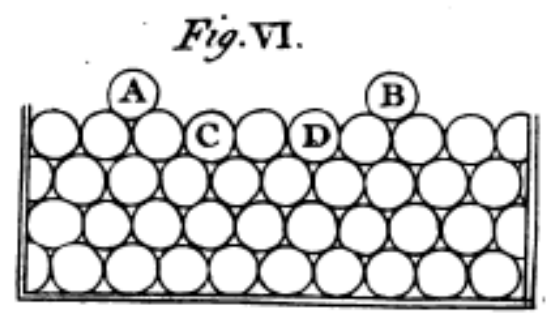

Fig. 2 - Ilustração de Franklin para representar a disposição das partículas de água em um recipiente.

p. 167-174), Franklin fez parte de um período materialista, em que as concepções de matéria e de éter vindas principalmente dos escritos de Newton desempenhou um papel relevante. Nesse sentido, a matéria é concebida como um arranjo de partículas duras, com tamanho e forma (Schofield, 1970, p. 7). Além do trabalho de Schofield (1970), ideias sobre a matéria no século XVIII podem ser encontradas em Thackray (1970). Sobre as concepções newtonianas de matéria, ver McMullin (1979).

21 A figura indicada por Franklin está presente no Plate I de seu livro.

22 Ou seja, as partículas de água na superfície têm mais facilidade em subir, por terem menos contato com outras partículas.

23 Franklin já havia discutido a ideia de conservação do fogo elétrico na segunda carta enviada a Collinson, em julho de 1747. Heilbron (1979, p. 330) sugere que, apesar de Franklin não ter criado a concepção de conservação do fogo elétrico, ele teria sido o primeiro a explorá-la mais detalhadamente. 
9. O oceano é composto por água, um [material] não-elétrico, e sal, um elétrico per se ${ }^{24}$.

10. Quando existe uma fricção nas partes próximas de sua superfície [do oceano], o fogo elétrico é coletado das partes abaixo. Ele é claramente visível durante a noite. Ele aparece na popa e na esteira de qualquer embarcação flutuante. Cada traço de um remo mostra isso, e cada quebrar de onda e espirro [de água]: nas tempestades todo o mar parece em chamas $^{25}$. As partículas de água desprendidas, então repelidas pela superfície eletrificada, retiram continuamente o fogo [elétrico] conforme ele é coletado. Elas sobem e formam nuvens, e essas nuvens são altamente carregadas, e retém o fogo [elétrico] até que elas tenham uma oportunidade de transferi-lo 26 .

11. As partículas de água ascendendo como vapor, se anexam às partículas de ar.

12. As partículas de ar são ditas como duras, redondas, separadas e distantes umas das outras. Cada partícula repelindo fortemente [p. 42] cada outra partícula, por meio do qual elas recuam uma da outra, tão longe quanto a gravidade comum permitir.

13. O espaço entre quaisquer três partículas repelindo igualmente umas às outras será um triangulo equilátero.

14. No ar comprimido, esses triângulos são menores. No ar rarefeito, eles são maiores.

15. O fogo comum ${ }^{27}$ unido ao ar, aumenta a repulsão ${ }^{28}$, aumenta os triângulos, e assim deixa o ar especificamente mais leve. Esse ar, no meio de ar mais denso, subirá.

16. $\mathrm{O}$ fogo comum, assim como o fogo elétrico, proporciona repulsão às partículas de água, e destrói a atração de coesão entre elas. Por isso, o fogo comum, assim como o fogo elétrico, auxilia na ascensão de vapores.

17. Partículas de água, não tendo fogo nelas, se atraem mutuamente. Três partículas de água

\footnotetext{
${ }^{24}$ Esse é o segundo argumento crucial de Franklin sobre a formação das tempestades. Como a água e o sal interagem no oceano, sendo ambos de naturezas diferentes, fogo elétrico é coletado, deixando a água do mar eletrificada. Dessa forma, os vapores que dela emergem estariam carregados de fogo elétrico, o que desempenharia um papel importante na formação de grandes tempestades.

$25 \mathrm{O}$ termo original utilizado por Franklin foi on fire, o que deve significar que todo o mar parece estar eletrizado e não em chamas.

${ }^{26}$ A partir deste item, Franklin descreveu um sofisticado mecanismo da produção das tempestades, fundamentado em suas concepções de eletricidade, particularmente suas ideias de transmissão do fogo elétrico. Nenhuma dessas explicações são aceitas atualmente, entretanto, é interessante notar - principalmente pela leitura dos trechos seguintes - como ele foi hábil em elaborar um complexo esquema de interações entre corpos eletrificados para explicar um fenômeno cotidiano, os temporais.

27 A concepção de fogo adotada por grande parte dos filósofos da época era a criada por Herman Boerhaave (16681738), em que o fogo é um fluido que se manifesta através de calor, luz, cor, expansão de corpos fluidos ou sólidos e queima ou fusão. Nesse caso, Franklin se refere ao fogo comum como o ente capaz de demonstrar calor nos corpos (COHEN, 1956, p. 227-228).

28 Segundo Cohen (1956, p. 482, nota §), nesse ponto Franklin utiliza o princípio newtoniano de que as partículas ordinárias de ar formam um fluido elástico devido à força de repulsão entre elas. A presença de calor (fogo comum) aumenta essa força repulsiva.
} 
então sendo unidas a três partículas de um triângulo de $\operatorname{ar}^{29}$, iriam, pelas suas atrações mútuas operar contra a repulsão do ar, encurtando os lados e diminuindo o triângulo, pelo qual essa porção de ar ficando mais densa, se afundaria para a terra com sua água, e não subiria para contribuir para a formação de uma nuvem.

18. Mas se todas as partículas de água unidas com [as partículas de] ar trouxerem consigo uma partícula de fogo comum, a repulsão do ar sendo assistida e reforçada pelo fogo, mais que obstruída pela atração mútua das partículas de água, o triangulo dilata, e essa porção de ar se tornando rarefeita e especificamente mais leve sobe.

19. Se as partículas de água trazem fogo elétrico quando elas [p. 43] se unem ao ar, a repulsão entre as partículas de água eletrificadas se junta à repulsão natural do ar, para forçar suas partículas para uma distância maior, assim os triângulos são dilatados, e o ar sobe, carregando consigo a água ${ }^{30}$.

20. Se as partículas de água trouxerem com elas porções dos dois tipos de fogo ${ }^{31}$, a repulsão das partículas de ar é ainda mais fortalecida e aumentada, e os triângulos são mais alargados.

21. Uma partícula de ar pode estar cercada por doze partículas de água do mesmo tamanho que ela, todas em contato com ela. E por mais [outras partículas] ligadas àquelas.

22. Partículas de ar carregadas ${ }^{32}$ dessa forma seriam atraídas para perto umas das outras pela atração mútua das partículas de água. O fogo, comum ou elétrico, não contribuiu para a repulsão entre elas.

23. Se o ar dessa forma carregado for comprimido por ventos opostos [a ele], ou por ser dirigido contra montanhas, etc. ou condensado pela retirada do fogo que o auxiliava em sua expansão, os triângulos contraem, [e] o ar com sua água descerá como orvalho. Ou, se água cercando uma partícula de ar entrar em contato com a água que cerca outra [partícula de ar], elas se juntam e formam uma gota, e [assim] nós temos chuva.

24. O sol fornece (ou aparenta fornecer) fogo comum para todos os vapores, sejam [eles] vindos da terra ou do mar.

25. Esses vapores que possuem ambos o fogo comum e o elétrico, são mais bem protegidos que aqueles que só possuem o fogo comum. Pois, quando os vapores sobem para [p. 44] as regiões mais frias acima da terra, o frio não vai diminuir o fogo elétrico se ele diminuir o [fogo] comum $^{33}$.

\footnotetext{
${ }^{29}$ Nesse ponto, é importante ressaltar que, na época de Franklin, não existia a concepção de uma molécula de água $\left(\mathrm{H}_{2} \mathrm{O}\right)$ ou de ar, por exemplo, oxigênio $\left(\mathrm{O}_{2}\right)$. Assim como muitos de sua época, ele pensou em elementos únicos, homogêneos em sua composição, como se houvesse um único elemento água e um único elemento ar. Para mais detalhes, ver Alfonso-Goldfarb e Ferraz (1993).

${ }^{30}$ Dessa forma, está explicado como os vapores de água eletrificados sobem até formar nuvens carregadas.

${ }^{31}$ Fogo elétrico e fogo comum.

${ }^{32}$ Nesse caso, o termo "carregadas" não indica uma eletrização, e sim o fato de a partícula de ar estar acompanhada de partículas de água.

${ }^{33} \mathrm{Ou}$ seja, mesmo que o vapor condense, ele ainda carregará o fogo elétrico.
} 
26. Por isso as nuvens formadas por vapores vindos de água doce na terra, de vegetais crescendo, terra úmida, etc. liberam sua água mais rápida e facilmente, possuindo pouco fogo elétrico para repelir e manter as partículas separadas. Assim a maior parte da água vinda da terra, cai na terra novamente. E os ventos soprando da terra para o mar são secos. Há pouca utilidade para a chuva no mar, e roubar da terra a sua umidade, a fim de chover no mar, não pareceria lógico.

27. Mas as nuvens formadas por vapores vindos do mar, tendo ambos os [tipos de] fogo, e particularmente uma grande quantidade de [fogo] elétrico, mantêm fortemente suas águas, elevando-as alto, e sendo movidas pelos ventos, poderão trazê-las [as águas] do meio do oceano profundo para o meio do continente ${ }^{34}$.

28. [A maneira] como essas nuvens do oceano, mantendo tão fortemente suas águas, são obrigadas a liberá-las na terra onde há necessidade, será considerado a seguir.

29. Se elas são direcionadas pelos ventos contra as montanhas, sendo essas montanhas menos eletrificadas, [elas] as atraem, e no contato roubam seus fogos elétricos (e, estando frias, [roubam] o fogo comum também). Consequentemente, as partículas se aproximam das montanhas e [se aproximam] entre elas. Se o ar não está muito carregado [de água], ela [a água] só cai em [forma de] orvalho no topo e nos lados da montanha, formando nascentes, e descendo para os vales em riachos, os quais juntos, formam córregos e rios maiores. Se muito carregado, o fogo elétrico [atrelado às partículas de água] é imediatamente tomado de toda [p. 45] a nuvem. E, ao deixá-la, emite uma luz brilhante e faz um barulho alto. As partículas se juntam instantaneamente pela deficiência daquele fogo, e caem em uma forte chuva ${ }^{35}$.

30. Quando uma cadeia de montanhas barra as nuvens dessa forma, e extrai o fogo elétrico da primeira nuvem se aproximando, aquela [nuvem] que vem em seguida, quando ela se aproxima da primeira nuvem, agora privada de seu fogo elétrico, lampeja nela, e começa a liberar a sua própria água. A primeira nuvem lampeja na montanha novamente. A terceira nuvem se aproxima, e todas as subsequentes, agindo da mesma maneira, não importando o tão longe que elas se estendem, que pode ser por centenas de milhas de território 36 .

31. Por isso [ocorrem] as tempestades contínuas de chuva, raios e trovões no lado leste dos Andes, que, estando de norte a sul, e sendo muito altos, interceptam todas as nuvens trazidas até eles pelo oceano Atlântico pela troca dos ventos, e as obriga liberar suas águas, pelas quais

\footnotetext{
${ }^{34}$ Franklin se refere aqui as nuvens vindas do oceano que, segundo ele, possuem mais fogo elétrico que aquelas formadas no continente. Estão explicadas assim porque as nuvens vindas do oceano provocam chuvas mais fortes, segundo Franklin, que aquelas produzidas no meio dos continentes.

35 Franklin estabelece aqui o que consideramos seu terceiro princípio crucial para a formação das tempestades, discutido de forma inicial no item 23 do texto: com o fogo elétrico transmitido, seja para uma montanha ou outra nuvem, a repulsão entre as partículas de ar que carregam partículas de água diminui. A atração mútua da água faz, então, com que elas se unam, produzindo chuvas ou orvalho, dependendo da concentração de água nas partículas de ar. Nesse item, ele faz referência novamente à sua teoria de transmissão de fogo elétrico. 36 Franklin indica aqui uma reação em cadeia para a transmissão do fogo elétrico, que é provocada pela primeira
nuvem e se segue por toda a extensão de nuvens que vem após ela.
} 
os grandes rios Amazonas, La Plata, e Oroonoko são formados, os quais retornam à água para o mesmo mar, depois de ter fertilizado um campo de grande extensão.

32. Se um território é plano, sem montanhas para interceptar as nuvens eletrificadas, ainda assim existem meios de fazer com que elas liberem sua água. Pois, se uma nuvem eletrificada vinda do mar, encontra no ar uma nuvem vinda da terra (e por isso não eletrificada ${ }^{37}$ ), a primeira lampejará seu fogo elétrico para a última, e assim ambas as nuvens deverão liberar suas águas repentinamente.

33. As partículas eletrificadas da primeira nuvem se aproximam quando perdem o seu fogo e as partículas da outra nuvem se aproximam [p. 46] o recebendo. Ambas têm assim a oportunidade de se juntarem em gotas. $\mathrm{O}$ choque ou o arranque dado ao ar, contribui também para derrubar a água, não somente dessas duas nuvens, mas das outras próximas a ela. Daí a chuva repentina imediatamente após luzes de relâmpagos.

34. Para mostrar isso por um fácil experimento: pegue dois pedaços redondos de papelão de duas polegadas de diâmetro. Do centro e circunferência de cada um deles suspenda, por fios de seda finos de dezoito polegadas, sete bolas pequenas de madeira, ou sete ervilhas de igual tamanho: assim as bolas anexadas a cada papelão formarão triângulos equiláteros iguais, uma bola estando no centro, e fixa a iguais distancias dela e de cada outra. E, assim, elas representam as partículas de ar. Molhe os dois conjuntos com água, e [com] algumas [partículas de água] aderindo-se a cada bola, eles [os conjuntos] representarão o ar carregado. Com destreza, eletrifique um conjunto, e suas bolas vão se repelir a uma distância maior, aumentando os triângulos. Se a água aderida nas sete bolas pudesse entrar em contato, ela formaria uma gota ou gotas tão pesadas que quebrariam a coesão que ela tinha com as bolas, e assim cairiam. Deixe os dois conjuntos representarem as duas nuvens, um [deles] sendo uma nuvem eletrizada do mar, e o outro uma nuvem [vinda] da terra ${ }^{38}$. Traga-os para dentro da esfera de atração ${ }^{39}$, e eles vão se atrair um em direção ao outro, e você verá assim as bolas separadas se atraindo. A primeira bola eletrificada que se aproxima por atração de uma bola não eletrificada se junta a ela, e dá fogo [elétrico] a ela. Instantaneamente, elas se separam, e cada uma voa para outra bola de seu próprio grupo, uma para [p. 47] dar, e outra para receber fogo. E assim isso acontece em ambos os conjuntos, mas tão rápido que quase de forma instantânea. Na colisão elas se sacodem e liberam suas águas, que representam a chuva 40 .

\footnotetext{
37 Porque as nuvens do solo possuem pouco fogo elétrico. Ver item 26 do texto.

$38 \mathrm{O}$ termo original utilizado por Franklin foi land cloud, o que quer dizer uma nuvem formada em terra firme.

39 A esfera de atração indicada por Franklin é o espaço em que as atmosferas elétricas dos dois corpos podem interagir e se atrair.

40 Trata-se, aparentemente, do estabelecimento de um equilíbrio de fogo elétrico nos dois conjuntos. Como a bola eletrificada de um perdeu fogo elétrico para a bola não eletrificada de outro, ela busca suprir a falta, indo em direção a outra bola eletrificada. No caso da bola recém-eletrificada, por atração, ela vai em direção às demais não eletrificadas. Esse processo causa o choque entre as bolas, o que contribui - assim como a equalização de fogo elétrico - para liberar as partículas de água atrelas às bolas dos dois conjuntos. O mesmo princípio funcionaria com as partículas de ar que possuíssem atreladas a elas partículas de água com fogo elétrico.
} 
35. Assim quando as nuvens [vindas] do mar e da terra passam a uma boa distância do raio, elas são atraídas entre si até a essa distância [da esfera de atração], pois a esfera de atração de eletricidade está muito além da distância da ocorrência do raio.

36. Quando um grande número de nuvens vindas do mar encontra um número de nuvens vindas da terra, os raios elétricos aparentam atingir diferentes partes. E, conforme as nuvens são empurradas e misturadas pelo vento, ou trazidas para perto pela atração elétrica, elas continuam dando e recebendo raios e mais raios, até o fogo elétrico ser igualmente difundido.

37. Quando o cano de uma arma (em experimentos elétricos) possui pouco fogo elétrico em si, você deve aproximar o seu nó [do dedo] bem perto, antes que você possa extrair uma faísca. Dê a ele mais fogo, e ele dará uma faísca a uma distância maior. Dois canos de arma unidos, e tão altamente eletrificados, produzirão uma faísca a uma distância maior ainda. Mas, se dois canos de arma eletrizados se afetarão a duas polegadas de distância, e farão um grande barulho, qual será a grande distância em que dez mil acres de nuvem eletrificada atingirá e liberará o seu fogo, e quão alto será esse barulho?

38. É uma coisa comum ver nuvens em diferentes alturas passando [por] diferentes caminhos, o que mostra diferentes correntes de ar, uma abaixo da outra. Conforme o ar entre os trópicos [p. 48] é tornado rarefeito pelo Sol, ele sobe, e o ar mais denso do norte e do sul pressionado para o seu lugar [do ar rarefeito]. $\mathrm{O}$ ar assim tornado rarefeito e forçado a subir, passa em direção ao norte e ao sul, e deve descer nas regiões polares ${ }^{41}$, se ele não tiver oportunidade antes, a fim de que a circulação possa continuar.

39. Conforme as correntes de ar, com as nuvens dentro [delas], passam em diferentes caminhos, é fácil de conceber como as nuvens, passando umas por cima das outras, podem atrair umas às outras, e assim se aproximar o suficiente para o golpe elétrico. E também, [é fácil conceber] como as nuvens elétricas podem ser carregadas para dentro da terra de bem longe do mar, antes que elas tenham uma oportunidade de golpear.

40. Quando o ar, com seus vapores levantados do oceano entre os trópicos, começa a descer nas regiões polares, e entrar em contato com os vapores levantados de lá, o fogo elétrico que ele [o ar] traz começa a ser comunicado, e é visto em noites claras, sendo primeiramente visíveis onde ele está primeiramente em movimento, isto é, onde o contato começa, ou na parte mais ao norte. Dali, os fluxos de luz aparentam disparar para o sul, até acima do zênite dos países do norte. Mas, ainda que a luz aparenta disparar do norte para o sul, o progresso do fogo é realmente do sul para o norte, o seu movimento começando no norte é a razão pela qual ele é visto primeiramente lá.

Pois o fogo elétrico nunca é visível, a não ser quando está em movimento, e pulando de um corpo para corpo, ou de partícula para partícula através do ar. Quando ele passa através de corpos densos, ele não é visto. Quando um fio faz parte de um ciclo, na explosão do frasco elétrico, o fogo, embora em uma grande quantidade [p. 49], passa invisível pelo fio. Mas, na passagem ao longo de uma corrente, ele se torna visível conforme ele pula de ligação a ligação.

${ }^{41}$ Uma vez que, nessas regiões, o ar se torna mais denso e, portanto, é forçado a descer. 
Ao passar ao longo de uma folha dourada, ele é visível. Pois, a folha de ouro é cheia de poros. Segure uma folha para a luz e ela parecerá uma rede, e o fogo será visto em seu pulo sobre os buracos. - E assim como quando um longo canal preenchido com água parada é aberto em uma das extremidades, para ser descarregado, o movimento da água começa primeiro perto da extremidade aberta, e prossegue para a extremidade fechada, ainda que a água se mova da [extremidade] fechada em direção à extremidade aberta. Assim, o fogo elétrico descarregado nas regiões polares, talvez de mil léguas de distância de ar vaporizado, aparece primeiro onde ele é primeiramente movido, i. e. na parte mais ao norte, e a aparição prossegue para o sul, embora o fogo se mova realmente para o norte. Isto é suposto para explicar a Aurora Boreal ${ }^{42}$. 41. Quando existe um grande calor na terra, em uma região especifica (tendo o sol brilhado nela talvez [durante] muitos dias, enquanto as terras vizinhas ficaram encobertas pelas nuvens) o ar inferior é rarefeito e sobe, o ar mais denso e gelado [que está] acima desce. As nuvens nesse ar se encontram de todos os lados, e se juntam no espaço aquecido. E se algumas estão eletrizadas, outras não, raios e trovões ocorrem, e a chuva cai. Daí [porque se formam] os temporais com raios e trovões depois do calor, e ar frio depois de temporais; a água e as nuvens que os trazem, vindas de regiões mais altas e, portanto, mais frias.

42. Uma faísca elétrica, extraída de um corpo irregular a partir de alguma distância, é dificilmente sempre reta, mas se mostra torta e [p. 50] ondulada no ar. E assim fazem os flashes dos raios, [já que] as nuvens são corpos muito irregulares 43 .

43. Conforme as nuvens eletrizadas passam em cima de um campo, montanhas e árvores altas, torres elevadas, pináculos, mastros de navios, chaminés, etc. assim como muitas proeminências e pontas, extraem o fogo elétrico, e toda a nuvem se descarrega lá44.

44. Perigoso, portanto, é se abrigar embaixo de uma árvore, durante um temporal com raios e trovões. Isso tem sido fatal para muitos homens e animais.

45. É mais seguro estar em um campo aberto por outra razão. Quando as roupas estão molhadas, se um raio em seu caminho para o chão caísse em sua cabeça, ele poderia correr pela água em volta da superfície do seu corpo. Enquanto que, se suas roupas estiverem secas, ele iria através

\footnotetext{
42 Ou seja, a Aurora Boreal seria a aparição do fogo elétrico enquanto ele caminha entre as partículas de diferentes vapores de ar, dos trópicos aos extremos norte ou sul do planeta.

43 Aqui Franklin coloca seu quarto argumento crucial, fazendo a primeira associação direta entre relâmpagos e faíscas elétricas. Está claro, para ele, que os dois têm a mesma natureza.

${ }^{44}$ Este item tem relação com os argumentos de Franklin em duas cartas anteriores, direcionadas a Peter Collinson. Nelas, Franklin argumenta sobre o poder de corpos pontudos em extrair e lançar fogo elétrico. Em uma dessas cartas, ele descreve um experimento - dentre muitos outros - que mostra esse poder, utilizando uma garrafa de Leyden, uma bala de ferro, uma bola de cortiça e um punhal. Eletrificando a bala, era possível observar que a bola de cortiça é repelida, mas quando o punhal foi acrescentado ao arranjo, ele destruiu a repelência que havia entre a bala e a cortiça. Foram feitas algumas variações desse mesmo experimento e verificou-se que quanto mais afiado o punhal era, melhor ele atraía a eletricidade. Com a observação desses fenômenos, Franklin chegou à conclusão de que as pontas eram capazes de atrair o fogo elétrico. Para demonstrar o poder das pontas de expulsar a eletricidade, foi colocada uma agulha junto à bala. Como a bala não poderia ser eletrificada nesse arranjo, Franklin concluiu que a agulha era capaz de expulsar o fogo elétrico.
} 
do seu corpo 45 .

Por isso um rato molhado não pode ser morto pela garrafa elétrica explodindo, enquanto um rato seco poderia [ser morto] ${ }^{b}$.

46. O fogo comum está em todos os corpos, mais ou menos, assim como fogo elétrico ${ }^{46}$. Talvez eles possam ser diferentes modificações de um mesmo elemento. Ou eles podem ser diferentes elementos. O último [argumento] é conjecturado por alguns [filósofos naturais].

47. Se eles são coisas diferentes, ainda assim eles podem subsistir e realmente devem [subsistir] juntos em um mesmo corpo.

48. Quando o fogo elétrico golpeia através de um corpo, ele age sobre o fogo comum contido nele [no corpo], e coloca esse fogo em movimento. E se ali existir uma quantidade suficiente de cada tipo de fogo, o corpo vai ser inflamado.

49. [p. 51] Quando a quantidade de fogo comum no corpo é pequena, a quantidade de fogo elétrico (ou de golpe elétrico) deverá ser maior. Se a quantidade de fogo comum é grande, menos fogo elétrico é suficiente para produzir o efeito [de inflamar o corpo].

50. Desse modo espíritos ${ }^{47}$ devem ser aquecidos antes de incendiarmos eles com a faísca elétrica. Se eles são muitos aquecidos, uma pequena faísca será [suficiente]. Se não, a faísca deve ser maior.

51. Até ultimamente nós podíamos incendiar apenas vapores aquecidos, mas agora nós podemos queimar resina seca e dura [com as faíscas elétricas]. E quando nós pudermos produzir grandes faíscas elétricas, poderemos ser capazes de incendiar não só espíritos que não foram aquecidos, assim como um relâmpago faz, mas até mesmo a madeira, dando agitação suficiente ao fogo comum contido nela, como nós sabemos que o atrito fará.

52. Vapores sulfurosos e inflamáveis vindos da terra, são facilmente acendidos por raios. Além daqueles vindos da terra, tais vapores são enviados por pilhas de feno úmido, milho, ou outros vegetais, que aquecem e fedem. Madeira apodrecendo em árvores ou edifícios antigos faz o mesmo. Tais são, portanto, fácil e frequentemente incendiados.

53. Metais são frequentemente derretidos por raios, embora talvez não pelo calor no raio, nem completamente pelo fogo agitado nos metais. Pois, como qualquer corpo pode se insinuar entre

\footnotetext{
45 Franklin coloca aqui a hipótese de que, caso uma pessoa molhada seja atingida por um raio, esse raio irá percorrer o caminho até o chão através da água que envolve o corpo da pessoa atingida. No caso de uma pessoa seca, o caminho percorrido pelo raio será através do corpo da pessoa, já que o corpo humano também é capaz de conduzir o fogo elétrico. Isso, obviamente, não é mais seguro.

b Isso foi tentado com uma garrafa, contendo cerca de um quarto. Foi então pensado que uma das grandes garrafas de vidro, mencionada nessas cartas, talvez tenha o matado, através da água.

46 Para Franklin, todos os corpos possuíam uma quantidade normal de fogo elétrico, que podia ser aumentada ou diminuída de acordo com as interações feitas com outros corpos. Assim como na teoria de Boerhaave, em que todos os corpos possuem o fogo comum, e os diferentes efeitos que podem ser percebidos em sua forma se dão pelo excesso ou pela abstinência de fogo (COHEN,1956, p. 228).

47 Os espíritos a que Franklin se refere provavelmente são formas metafóricas de representar princípios ou poderes vitais nas substâncias. Ver o verbete spirit no Online Etymology Dictionary (http://www.etymonline.com, acesso em Maio de 2017).
} 
as partículas de metal, e superar a atração pela qual eles se juntam (como mênstruos 48 diversos [p. 52] podem) vão fazer o sólido se tornar fluido, assim como o fogo, ainda sem aquecê-lo. Assim, o fogo elétrico, ou o raio, criando uma violenta repulsão entre as partículas do metal pelo qual ele passa, o metal é fundido 49 .

54. Se você, por um violento fogo, derretesse a extremidade de um prego, que estivesse metade pregado em uma porta, o calor dado a todo o prego antes que uma parte derretesse deve queimar a placa na qual ele está pregado. E a parte derretida queimaria o chão sobre o qual ela cai. Mas, por um raio, uma espada pode ser derretida na bainha e [também pode ser derretido] dinheiro no bolso de um homem, sem queimar ambos, isso deve ser uma fusão a frio ${ }^{\mathrm{c}}$.

55. Raios rasgam alguns corpos. A faísca elétrica atacará um buraco através de um bloco de papel forte.

56. Se a origem dos raios, atribuído neste trabalho, for a verdadeira, deve haver poucos trovões ouvidos no mar longe da terra. E, de acordo com alguns velhos capitães do mar, a quem algumas perguntas foram feitas, realmente afirmam que o fato concorda perfeitamente com a hipótese. Pois, na travessia do grande oceano, eles raramente se deparam com trovões até que eles entram em sondagens ${ }^{50}$. E que as ilhas distantes do continente têm muito pouco disso [trovão]. E um observador curioso, que viveu 13 anos nas Bermudas, diz, [que] ocorreram menos trovões lá, em todo esse tempo, que ele tenha ouvido algumas vezes em um mês na Carolina ${ }^{51}$.

\section{Agradecimentos}

Os autores agradecem o apoio da Fundação de Amparo à Pesquisa do Estado de São Paulo (FAPESP) para a realização dessa pesquisa.

\section{Referências bibliográficas}

ALFONSO-GOLDFARB, A. M.; FERRAZ, M. H. M. As possíveis origens da química moderna. Química Nova, v. 16, n. 1, p. 63-68, 1993.

ALLCHIN, D. Teaching the nature of science: perspectives and resources. St. Paul, MN: SHiPS Education Press, 2013.

\footnotetext{
48 Em termos gerais, mênstruos são líquidos dissolventes.

${ }^{49}$ Nesse caso Franklin atribui o derretimento dos metais ao fogo elétrico transmitido pelo raio, e não pelo calor produzido por ele.

c Esses fatos, embora contados em vários relatos, são agora uma dúvida, uma vez que tem sido observado que as partes de um badalo do sino que caiu no chão [por ter sido] quebrado e parcialmente derretido por um raio, realmente queimou as placas [sobre as quais ele caiu]. (Veja Philos. Trans. Vol LI. Parte I e Sr. Kinnersley descobriu que um fio de ferro fino, derretido pela Eletricidade, tem o mesmo efeito).

${ }^{50}$ Franklin se refere ao momento em que se entra uma área em que é possível ouvir os trovões, ou seja, quando se está próximo de terra firme.

51 Provavelmente, referindo-se aos estados da Carolina do Sul e Carolina do Norte.
} 
BATISTA, G. L. F.; DRUMMON, J. M. H. F; FREITAS, D. B. Fontes primárias no ensino de física: considerações e exemplos de propostas. Caderno Brasileiro de Ensino de Física, v. 32, n. 3, p. 663-702, 2015.

BOSS, S. L. B.; ASSIS, A. K. T.; CALUZI, J. J. Stephen Gray e a descoberta dos condutores e isolantes: tradução comentada de seus artigos sobre eletricidade e reprodução de seus principais experimentos. São Paulo: Cultura Acadêmica, 2012.

BOSS, S. L. B.; CALUZI, J. J. Os conceitos de eletricidade vítrea e resinosa segundo Du Fay. Revista Brasileira de Ensino de Física, v. 29, n. 4, p. 635-644, 2007.

CHAPLIN, J. E. The First Scientific American: Benjamin Franklin and the Pursuit of a Genius. New York: Basic Books, 2006.

COHEN, I. B. Franklin and Newton. Philadelphia: The American Philosophical Society, 1956.

Benjamin Franklin's Science. Harvard University Press, 1996.

. Benjamin Franklin. In: BENJAMIN, C. (Ed.) Dicionário de biografias científicas.

Rio de Janeiro: Contraponto, 2007.

DOBBS, B. J. T.; JACOB, M. Newton and the culture of newtonianism. New York: Humanity Books, 1995.

FRANKLIN, B. Experiments and observations on electricity, made at Philadelphia in America. $4^{\text {th }}$ ed. London: [s.n.], 1769.

. Autobiografia. São Paulo: Editora Martin Claret, 2005.

HANS, N. New trends in education in the 18th century. London: Routledge, 1998.

HEILBRON, J. L. Electricity in the 17th and 18th centuries - a study of early modern physics. Berkeley/ Los Angeles/ London: University of California Press, 1979.

KRAGH, H. Ideologia e mitos na História da Ciência. In: KRAGH, H. Introdução à Historiografia da Ciência. Porto: Porto Editora, 2001.

MARTINS, R. A. Introdução: a história das ciências e seus usos na educação. In: SILVA, C. C. Estudos de História e Filosofia das Ciências: subsídios para aplicação no ensino. São Paulo: Livraria da Física, 2006. p. xvii-xxx.

McMULLIN, E. Newton on matter and activity. Notre Dame: University of Notre Dame Press, 1978. 
MOURA, B. A. A aceitação da óptica newtoniana no século XVIII: subsídios para discutir a natureza da ciência no ensino. 2008. Dissertação (Mestrado em Ensino de Ciências) - Instituto de Física, Faculdade de Educação, Universidade de São Paulo, São Paulo.

PYENSON, L. Ética e ideologia na ciência de Nollet e Franklin. História, Ciências, Saúde, Manguinhos, v. 5, n. 1, p. 7-34, 1998.

SCHOFIELD, R. Mechanism and materialism: British natural philosophy in an age of reason. Princeton: Princeton University Press, 1970.

. An evolutionary taxonomy of eighteenth-century newtonianisms. Studies in Eighteenth-Century Culture, v. 7, p. 175-92, 1978.

SILVA, C. C.; PIMENTEL, A. C. As atmosferas elétricas de Benjamin Franklin e as interações elétricas no século XVIII. In: MARTINS, R. A.; SILVA, C. C.; FERREIRA, J. M. H.; MARTINS, L. A' C. P. (Eds.). Filosofia e história da ciência no cone sul - seleção de trabalhos do $5^{\circ}$ encontro. Campinas: Associação de Filosofia e História da Ciência do Cone Sul, 2008a. - Uma análise da história da eletricidade presente em livros didáticos: o caso de Benjamin Franklin. Caderno Brasileiro de Ensino de Física, v. 25, n. 1, p. 141-159, 2008b. SILVA, C. C. Jean Antoine Nollet contributions to the institutionalization of physics during the $18^{\text {th }}$ century. In: KRAUSE, D.; VIDEIRA, A.A.P. (Org.). Brazilian Studies in History and Philosophy of Science. Dordrecht: Springer, 2011.

THACKRAY, A. Atoms and powers: an essay on Newtonian matter-theory and the development of chemistry. Cambridge-MA: Harvard University Press, 1970.

WHITTAKER, E. A history of the theories of aether and electricity. London: Thomas Nelson and Sons Ltd, 1951. 